\title{
The Twisting Path of Concept Development in Learning to Teach
}

\author{
PETER SMAGORINSKY, LESLIE SUSAN COOK, AND \\ TARA STAR JOHNSON
}

University of Georgia

Teacher education is often viewed as too theoretical and not sufficiently concerned with the realities of classroom practice. From this perspective theory and practice are cast as distinct realms whose only connection comes when theory influences practice. We argue that the theory-practice dichotomy lacks the richness of Vygotsky's notion of concepts, in which abstract principles are interwoven with worldly experience. More specifically, Vygotsky distinguishes two types of concepts, spontaneous concepts and scientific concepts. Spontaneous concepts are learned through cultural practice and, because they are tied to learning in specific contexts, allow for limited generalization to new situations; scientific concepts are learned through formal instruction and, because they are grounded in general principles, can more readily be applied to new situations. Vygotsky argues that while spontaneous concepts may be developed without formal instruction, scientific concepts require interplay with spontaneous concepts; hence the problematic nature of the theory-practice dichotomy. He further identifies two types of generalization that approximate concepts yet do not achieve their theoretical unity: complexes, in which some members of the set may be unified with others but all are not unified according to the same principle; and pseudoconcepts, in which members of the set appear unified but include internal inconsistencies. We argue that teacher educators should strive to teach concepts, though the overall structure of teacher education programs makes it more likely that their students will learn complexes or pseudoconcepts. We illustrate these problems with examples from case studies of teachers making the transition from their teacher education programs to their first jobs.

Many educators believe that teacher education programs are too theoretical, emphasizing ideals and abstractions at the expense of the mundane tools needed for effective practice (Baldassarre, 1997; Gallagher, 1996; Kallos, 1999; Voutira, 1996). This schism is revealed in the lament of a teacher who, when asked about the value of contemporary literary theory to her instruction, responded that theories are "far removed from those of us who work the front lines!" (Applebee, 1993, p. 122). Wilhelm 
(1997) relates a story told among teachers in which an out-of-touch professor, after observing teachers at work, wonders, "Well, yes. It all looks very good in practice. But my question is: will it work in theory?" (p. 22, emphasis in original).

In this view theory and practice are set up as different concerns, with university-based faculty, aloof within the ivory tower, espousing ideals and the principles that govern them, while school-based teachers engage in practice in the teeming world of the classroom. Common phrasings bespeak the degree to which these two realms are seen as in or out of touch with one another and the directional flow of authority on those occasions when they do come in contact. Often theory is pitted versus practice (e.g., Colorado Writing Tutors Conference, 2000) or viewed as the opposite of practice (Chambers, 1992). Theory is typically regarded as something that can be put into practice (Kearsley, 2001) or even into practitioners (Jackson, 1992), or that can have an effect on practice (Association for Computing Machinery, 1997). Common metaphors suggest that the chasm between theory and practice might be bridged (Weaver, 1998), that the two discrete realms might be linked (Grisham \& Brink, 2000), that they might be joined in marriage (Ballenger, 1999), or that they might be integrated (Beyer, 1996). This coupling typically involves a distinct hierarchy, with influence proceeding from theory to practice (ERIC Clearinghouse on Reading English and Communication, 1995) or serving as a guide to practice (Chambers, 1992). All of these phrasings position theory and practice as separate domains, with theory the more ethereal and authoritative and practice the more protean and pragmatic. While, it seems, theory can leap the gulf to improve practice, practice has little effect on theory, a view contested by those practitioners who study their own teaching (e.g., MacLean \& Mohr, 1999). Yet the dichotomous, hierarchical conception of theory standing above practice, and often practitioners, remains axiomatic among many in the academy (Stephens et al., 1999).

Dictionary definitions of theory reinforce its lofty and distinct nature. Merriam-Webster (1996) defines theory as "The general or abstract principles of a body of fact, a science, or an art.... an ideal or hypothetical set of facts, principles, or circumstances." Practice, on the other hand, is "actual performance or application (ready to carry out in practice what they advocated in principle)" (Merriam-Webster, 1996; emphasis in original). Here again, practice is separate from theory (what is advocated in principle); practice is what people do, perhaps in spite of what they think.

Smith (1999) traces the disengagement of theory and practice to Aristotle's threefold classification of disciplines as theoretical, productive, or practical, proposed in The Nicomachean Ethics in 350 BCE. The belief in the separation of theory and practice thus has persisted for millennia. As Cohen (1988) has argued, any longstanding belief about education is difficult to 
displace, no matter how well grounded an alternative might be. Perhaps ironically, our purpose in this paper is to make a theoretical contribution that, we hope, provides a useful alternative to the theory/practice divide. Drawing on Vygotsky's (1987) outline of concepts, we hope to show that focusing on theory and practice, and particularly their separation, misses the point of how people learn. Rather, we argue that one's development of an approach to teaching stands in dialectical relation to one's development of a conception of teaching, which comes about through principled (i.e., systematic and rule-governed) activity in social context. Making this argument requires rejecting the theory-practice binary and recognizing the inherent relation between abstracted systems of principles and engagement in cultural practice that is revealed through Vygotsky's notion of the concept.

We next review the main terms of this argument. We begin with a review of Vygotsky's (1987) distinction among concepts, pseudoconcepts, and complexes (see Figure 1). Our goal with this review is to replace the notion of theory with the construct of the concept in outlining a Vygotskian version of teaching and teacher education. Concepts, as we later review, are not distinct from social practice but grounded in worldly experience. We then outline a more robust version of practice than appears in the bifurcated view of theory and practice we described previously. The view we propose regards practice as involving the kinds of recurring cultural activity through which concepts are reinforced and modified. Ultimately, our goal is to argue that the problem with teacher education is not too much theory, but too little concept (cf. Cook, Smagorinsky, Fry, Konopak, \& Moore, 2002).

Yet this process of early-career teachers' concept development is problematic for teacher educators for a number of reasons. Achieving unity in a concept does not come easily or immediately but rather follows a "twisting path" (Vygotsky, 1987, p. 156) that requires a gradual process (Sanford, 1999), becoming modified as people gain new experiences and apply it in new settings. Using examples from research conducted through the Center on English Learning and Achievement (CELA) in which we have studied the transition made by students moving from teacher education programs into their first jobs, we review a number of factors that teacher educators need to address if they are to promote development toward particular concepts among their students.

THEORETICAL FRAMEWORK: AN ACTIVITY THEORY PERSPECTIVE CONCEPT, PSEUDOCONCEPT, AND COMPLEX

Vygotsky (1987) was concerned with the ways in which people develop concepts over time. To Vygotsky word meaning is the appropriate unit of 


\begin{tabular}{|c|c|c|c|}
\hline & Definition & Child's Example & Teacher's Example \\
\hline Complex & $\begin{array}{l}\text { The individual } \\
\text { elements are } \\
\text { associated with one } \\
\text { another but not all are } \\
\text { associated according } \\
\text { to the same theme or } \\
\text { significant traits. }\end{array}$ & $\begin{array}{l}\text { Learning to label a canine a } \\
\text { dog and then labeling any } \\
\text { other 4-legged creature a } \\
\text { dog. }\end{array}$ & $\begin{array}{l}\text { Learning to label a group } \\
\text { activity cooperative } \\
\text { learning and then labeling } \\
\text { any group activity } \\
\text { cooperative learning even } \\
\text { if students neither } \\
\text { cooperate nor learn. }\end{array}$ \\
\hline Pseudoconcept & $\begin{array}{l}\text { The individual } \\
\text { elements appear to be } \\
\text { unified but have } \\
\text { internal } \\
\text { inconsistencies }\end{array}$ & $\begin{array}{l}\text { Learning to label a canine a } \\
\text { dog and then labeling any } \\
\text { canine-like creature (e.g., } \\
\text { fox) a dog. }\end{array}$ & $\begin{array}{l}\text { Learning to label a group } \\
\text { activity cooperative } \\
\text { learning and then labeling } \\
\text { any group activity } \\
\text { cooperative learning even } \\
\text { if it lacks some critical } \\
\text { element such as } \\
\text { teamwork, a shared goal, } \\
\text { individual and group } \\
\text { accountability, and so on. }\end{array}$ \\
\hline Concept & $\begin{array}{l}\text { The individual } \\
\text { elements included in } \\
\text { the set are unified by a } \\
\text { single theme. }\end{array}$ & $\begin{array}{l}\text { Learning to label a canine a } \\
\text { dog and discriminating } \\
\text { between dogs and other } \\
\text { dog-like creatures. }\end{array}$ & $\begin{array}{l}\text { Learning to label an } \\
\text { activity cooperative } \\
\text { learning when small, } \\
\text { heterogeneous groups of } \\
\text { students work as a team } \\
\text { toward a shared goal in } \\
\text { such a way as to be both } \\
\text { individually and } \\
\text { collectively accountable } \\
\text { for the work, and work in } \\
\text { such a way as to show } \\
\text { cooperation and concern } \\
\text { for one another and thus } \\
\text { raise students' confidence } \\
\text { and self-perceptions. }\end{array}$ \\
\hline
\end{tabular}

Figure 1. Types of Generalization in Developmental Order.

analysis for studying the development of consciousness, which he equates with the development of concepts. Through the meanings that they attribute to words, people reveal the degrees of abstraction that they have achieved in their thinking. Vygotsky argues that "the speech of those who surround the child predetermines the paths that the development of the child's generalizations will take" (p. 143). Thus, through their transactions with other people, children appropriate meanings that are held by culture, both for literal meaning (cannibal refers to a person who eats people) and the value systems implied by their use (being a cannibal does or does not violate a sense of what it is to be human). To become a member of 
a community of practice with normative ways of acting and being understood-even if one's goal is to disrupt those norms - a learner needs to come to the same understanding for words that elders and other societal veterans have for them. The development of concepts thus involves growing into a culture's values and practices, with the culture in turn growing and changing as its practitioners contribute their understanding of its concepts.

Vygotsky (1987) identifies two types of concepts, scientific and spontaneous. Wertsch (1991; cf. Luria, 1976) argues that the Russian term naychnoe ponyatie, typically translated as scientific concept, is more properly translated as "academic" (p. 39) because people learn such concepts through formal, systematic instruction. As Vygotsky says, "The basis of [scientific concepts'] development is that they have their source in school instruction" (p. 214), thus limiting the availability of scientific concepts to those cultures that provide formal education of some kind. Vygotsky distinguishes scientific concepts from spontaneous concepts, which are generalizations learned informally through practical activity and everyday social interaction. Vygotsky valorizes scientific concepts as the height of intellectual activity because formal, abstracted knowledge of a concept enables one to reapply it to a new situation. Spontaneously developed concepts in contrast tend to be situated in the context in which they are learned and are thus less amenable to abstraction to new situations. His distinction is consistent with the idea that what is known as theory-typically developed in the academy - is a different, higher, and more easily transferred form of achievement than generalizations made strictly through experience or practice. Yet, as we later discuss, his notions of concept and practice involve an inherent relation that is absent from typical beliefs about theory and practice.

Concepts are distinguished by the fact that all of the individual elements they encompass are unified by a single theme. Along the path toward concepts, people develop complexes and pseudoconcepts, both of which approximate the unity of elements found in concepts but include inconsistencies.

A complex lacks the unity of both scientific and spontaneous concepts and the formal, abstract logic that underlies a scientific concept. Vygotsky argues:

If empirically present, any connection is sufficient to lead to the inclusion of an element in a given complex... The concept is based on connections of a single, logically equivalent type. In contrast, the complex is based on heterogeneous empirical connections that frequently have nothing in common with one another. (p. 137, emphasis in original) 
Items grouped under the aegis of a complex therefore are linked according to shared properties, though not all are linked according to the same property. At the level of the young child (Vygotsky's primary interest as a researcher), a youngster might first encounter a body of water and learn to name it a pond, and then name other bodies of water ponds as well-swimming pools, water holes, oceans, puddles and so on. Similarly, a teacher might learn that an instructional scaffold is a teacher-initiated effort to support learners' early efforts at appropriating new ideas or strategies and believe that extensive lecturing always provides such support, even if students are not listening to the lectures.

A pseudoconcept bridges the complex and concept developmentally. A pseudoconcept is a "shadow of the concept, one that reproduces its contours" (Vygotsky, 1987, p. 144), having all of the appearances of a concept yet connecting the objects "on the basis of simple association" (p. 142). Vygotsky distinguishes a concept from a pseudoconcept with the analogy that "the pseudoconcept is as similar to the true concept as the whale is to the fish" (p. 144). Internal contradictions prevent a pseudoconcept from being a concept. In the course of development, a learner goes from the highly associative complex, to the apparently conceptual yet internally contradictory pseudoconcept, to the unified concept.

This process of concept development is mediated by activity in cultural practice. Vygotsky (1987) argues that instruction in principles alone will not result in the development of a concept; rather, knowledge of abstracted governing rules must come in conjunction with empirical demonstration, observation, or activity. Vygotsky maintains:

Direct instruction in concepts is impossible. It is pedagogically fruitless. The teacher who attempts to use this approach achieves nothing but a mindless learning of words, an empty verbalism that simulates or imitates the presence of concepts in the child. Under these conditions, the child learns not the concept but the word, and this word is taken over by the child through memory rather than thought. Such knowledge turns out to be inadequate in any meaningful application. This mode of instruction is the basic defect of the purely scholastic verbal modes of teaching which have been universally condemned. It substitutes the learning of dead and empty verbal schemes for the mastery of living knowledge. (p. 170)

What Vygotsky describes here sounds like the account of theory outlined previously, involving principles divorced from application. His postulation requires the learner to establish a mindful relation between abstracted 
knowledge and experience in the world: "Conscious instruction of the pupil in new concepts (i.e., in new forms of the word) is not only possible but may actually be the source for a higher form of development of the child's own concepts, particularly those that have developed in the child prior to conscious instruction" (p. 172, emphasis in original).

Vygotsky (1987) argues that this interplay between formal knowledge of principles and knowledge gained through activity enables people to think about problems beyond their range of experience. He maintains that the "process of concept formation requires ... acts of thought which are associated with free movement in the concept system, with the generalization of previously developed generalizations, and with a more conscious and voluntary mode of operating on these existing concepts" (p. 181). The development of a scientific concept thus relies on formal instructionusually in an academic setting but available through communities of faith, apprenticeship relationships, organized sports, and other explicit and systematic instructional settings - and on the learner's conscious awareness and volition. It further relies on interplay within the learner's conceptual field, with a dialectical relation developing between scientific and spontaneous concepts, those that involve "situationally meaningful, concrete applications, that is, in the sphere of experience and the empirical.... Scientific concepts restructure and raise spontaneous concepts to a higher level" (p. 220). The formal principles of the scientific concept create cultural schemata that enable a greater understanding of worldly experience. This worldly experience has been described at length by sociocultural theorists who refer to it as cultural practice, the next area we outline.

Before departing this section we wish to stress the dynamic nature of a concept. Our discussion thus far might suggest that concept development is overly mechanistic, an exercise in categorization. Engagement with and development of concepts requires, however, extensive knowledge and experience-what we next describe as practice-with the concept and that to which it applies. Understanding instructional scaffolding, for instance, might require knowledge of how diverse learners require a variety of early support methods for their learning, how diverse learners may have diverse goals for being in school, how students with emotional or cognitive differences may respond to particular forms of instruction, how the physical context of learning does and does not support particular kinds of learning, how scaffolding when rigidly implemented may emphasize a teacher's goals at the expense of the learners'(Dyson, 1990; Searle, 1984), and other aspects of the dynamic relationship among teachers, learners, mediating tools, goals for participation, and the setting of instruction. This understanding goes well beyond simple categorizing, requiring instead the ability to understand and act within networks of social relationships. 


\section{PRACTICE}

Practice refers to the kind of activity central to the development of spontaneous concepts and implicated in the development of scientific concepts. The notion of practice outlined in the Vygotskian tradition is conceptually richer than that typically found in the theory-practice dichotomy, grounded more in culture and emerging from the history of social engagement taking place in what Lave and Wenger (1991) call communities of practice. Just as we see the concept as necessarily tied to experience, we see practice as necessarily involving principled behavior that emerges from the conventions provided by social genres: the recurring routines, codes, and representations that structure human activity. Scribner and Cole (1981) argue that practice is "a recurrent, goal-directed sequence of activities" (p. 236). With their emphasis on the recurring nature of activity, they implicitly position practice within broader, culturally grounded engagement with social others in historically developed patterns. Carr and Kemmis (1986) stress the ideological nature of practice, using the more robust term praxis introduced by Freire (1972) to describe recurring social action that shapes and changes the world.

Another notable facet of Scribner and Cole's (1981) conception of practice is its goal-directed nature. In this sense practice is primary. That is, social practices structure activity within the settings that people enter and in which they learn conventions for acting normatively. These normative actions and the goals toward which they are directed are not simply personal but are tied to broader cultural goals, what Leont'ev (1981) calls the motive of a setting that provides participants in cultural practice with a sense of telos or optimal outcome toward which social action proceeds (Wertsch, 2000). The idea of what is optimal is in the eye of the beholder, or is the shared vision of a community of beholders. The Nazi ideal for optimal outcome, Aryan Supremacy, while shared and fought for by many Europeans in the 1940 s, was rejected and contested by others across the continent and around the world.

People engage at some level in joint activity with other people and the artifacts of cultural practice (Cole, 1996), thus making learning to teach an inherently social experience rather than the solitary, if often lonely, process described by Bullough (1989) and others. Lave and Wenger (1991) argue further that "learning is not merely situated in practice ... learning is an integral part of generative social practice in the lived-in world" (pp. 34-35). This notion that social practice and learning are inseparable is a key insight to resolve the theory versus practice conundrum. According to this perspective, practice contributes to learning and thus to concept development, working in dialectical relation with the principles that bring order and unity to concepts. 
In the world of teacher education and career development, university programs and schools provide the foremost settings for learning how to teach; other settings might include professional organizations, online discussion communities, and other settings. These settings often have different motives, such as when university programs view the optimal teacher as one who has a critical consciousness and schools regard the optimal teacher as who respects, models, and reinforces the values of the community. Accompanying these differing goals are different ideologies and attendant social practices through which to achieve them, a great point of disjuncture for student teachers who must simultaneously play roles in both settings (Grossman, Smagorinsky, \& Valencia, 1999).

Within these settings, people engage in cultural practice through their use of what are variously known as artifacts (Cole, 1996), tools (Wertsch, 1991), and mediational means (Wertsch, 1991); that is, implements that hold the residue of prior cultural practice and enable one to act on the world, typically according to the precedents provided by cultural antecedents and modified in response to new problems and situations. Tools thus both afford cultural practice in that they provide a means of action and constrain new action through the specific purposes suggested by prior use. Tools can then be seen as liberating in their enabling function or limiting in that their historical uses may preclude new ways of thinking (Wertsch, 1991). Tools - whether tangible such as a hammer, ephemeral such as speech, or impalpable such as a speech genre-suggest rather than dictate appropriate practice and social trajectories, creating potential for particular kinds of action that may be realized in different ways by different participants (Smagorinsky, 2001; Wertsch, 1998).

In our work we have tried to identify the tools that early-career teachers are encouraged to appropriate and the attributions they make regarding where they learned to use those tools (Grossman et al., 1999). Different tools for teaching are embedded in different ideologies and directed toward different ends. For instance, the conceptual tool that some of our research participants called integrations - that is, weaving different curricular goals and materials together to enable students to construct new knowledge for themselves - came from a university program emphasizing constructivist teaching. Creating such integrations was difficult for preservice teachers who taught in schools with compartmentalized curricula and scripted lessons. This example illustrates the problem of enacting a concept-based praxis when the ideological motive of the setting of teaching suggests the employment of a radically different tool kit of mediational means and related cultural practices.

Taken together, these accounts of practice view it as necessarily tied to the development and refinement of a worldview through cultural engagement with significant social others. Given its inherent relation to the pursuit of 
cultural goals and its reliance on cultural tools, practice is conceptual in nature, or, in lesser degrees, pseudoconceptual or complexual in nature. Practice serves as the worldly experience through which a concept derives its grounding, coherence, and meaning. Practice is thus central to the interplay within the learner's conceptual field that integrates scientific and spontaneous concepts and enables one to generalize more broadly from immediate experience to new experiences through which a concept may be more formally and discriminatingly refined.

\section{EMPIRICAL BASIS OF REVIEW}

We next review case study research we conducted on the transition that teachers make from preservice teacher education programs to their first jobs (Cook et al., 2002; Grossman et al., 1999; Johnson, Smagorinsky, Thompson, \& Fry, in press; Smagorinsky, 1999b; Smagorinsky, Cook, Jackson, Moore, \& Fry, 2003; Smagorinsky, Lakly, \& Johnson, 2002). The overall design was created by the first author, Pamela Grossman, and Sheila Valencia for research conducted under the auspices of the National Research Center on English Learning and Achievement (CELA).

For each case study participant, interviews were conducted before both student teaching and the first year of full-time teaching to elicit background information about participants' experiences and conceptions of teaching. Data collection took place during both student teaching and the first year of full-time teaching in three observation cycles. Each cycle consisted of a preobservation interview, an observation of at least two classes that produced field notes, and a post-observation interview. The preobservation interview was designed to obtain information about the teacher's experiences leading up to and the plans for the upcoming observation, with particular attention to understanding the sources of the various pedagogical tools used during the classes. The postobservation interview's purpose was to verify what the researcher had observed and extend the line of questioning initiated in the preobservation interview. The observations both provided material for the interviews and corroborated the participant's accounts of practice. Interviews were also conducted with mentor teachers, relevant administrators, and university supervisors about the guidance they were providing. All interviews were recorded and transcribed for analysis.

Supplementary artifacts were collected from each key setting, such as course syllabi from university programs and curricula from schools. The cohort of participants from each university site in the research also produced concept maps before and after student teaching. The purpose of the concept map activities was to contribute to our understanding of how 
both individuals and cohorts conceived of their university program's purposes and emphases.

The data were read and analyzed using the Atlas.ti qualitative data analysis software to code each observation and interview. The interviews and field notes were analyzed to identify the pedagogical tools that were emphasized in the different settings of the participants' teaching. Each tool was coded in each of the following categories derived from activity theory:

- Name of tool, which included dozens of tools, including thematic teaching, workbook exercises, writing workshop, daily oral language, quizzes/tests, and so on

- Type of tool, which described whether a pedagogical tool was conceptual (i.e., capable of being abstracted to apply to many circumstances, such as instructional scaffolding) or practical (i.e., more immediately applicable, such as having students write in journals)

- Area of teaching in which the tool was emphasized, including student diversity, management, teaching, learning theory, assessment, writing, speaking/listening, reading, and language

- Attribution by participant regarding where he or she had learned of the tool, including apprenticeship of observation, teacher education coursework, mentor teacher, school administrator, university supervisor, colleagues at site, curriculum materials, professional development activities, mandates, and others

- Problem toward which the tool was applied, including student learning, identity, context surrounding classroom (e.g., policy), relationships, motivation, perception of students, control, classroom logistics, and classroom interactions

This analysis enabled inferences regarding the types of pedagogical tools emphasized in different settings and thus the conceptions of teaching emphasized in each site.

\section{IMPLICATIONS FOR TEACHER EDUCATION AND PROFESSIONAL DEVELOPMENT}

Our effort thus far has been to argue that the theory-practice binary is misguided and to propose that for teacher educators it is more important to stress concepts in their instruction of teachers. However, we have found in both our instruction of preservice teachers and our research on early-career teachers that advocating an emphasis on concepts is easier said than done. The purpose of this review is to outline a series of problems involved in the 
challenge of teaching preservice teachers concepts that are tied to their instructional practice. The general problem we identify concerns the ways in which teacher education programs are situated within constraints, mandates, financial limitations, and conflicting perspectives that make it difficult to teach a concept. It is more likely, we argue, that students will emerge from a teacher education program with a complex or pseudoconcept for teaching. Given the limited likelihood that schools will reinforce the same concept that a college of education will attempt to instill (Feiman-Nemser \& Buchmann, 1985), whatever degree of concept that a teacher learns in preservice education is likely to recede or be reformulated in light of new communities of practice that teachers become involved with at work. In these settings practitioners are likely to use different terminologies (i.e., the words themselves) and hold different values (the concepts associated with words) than are stressed in teacher education programs. The challenge of teaching concepts then is twofold: how to provide an activity setting in university programs in which an approach is presented consistently and is grounded in experiences with teaching, and how early-career teachers adapt that approach in school settings given the limited likelihood that the university and school cultures will be well aligned.

One challenge in considering teachers' development of concepts is that there is no agreement on the overall purpose of education, making pedagogical concept development a decidedly open-ended process. A conception of teaching is tied to one's notion of what qualities are embodied by the ideal person (Smagorinsky, 1999a; Smagorinsky \& O'Donnell-Allen, 2000). The ideal citizen has been variously identified as being caring (Noddings, 1993), subversive (Postman \& Weingartner, 1987), culturally literate (Hirsch, 1987), virtuous (Bennett, 1993), and imbued with countless other traits. Conceptions of teaching that follow from these notions may vary dramatically. Teaching and learning a conception of teaching, then, is complicated by the fact that the various stakeholders encountered while learning to teach may emphasize very different values and goals for the whole of education and for how it should be practiced.

We organize our assay according to a series of questions that have perplexed us throughout our consideration of the question of the role of concept development in learning to teach. These questions include the following:

1. How many concepts, and which of the many available, should a teacher education program emphasize?

2. Who owns the concept; that is, how does one arrive at a definition for a concept, given that each may be contested by different people claiming authority regarding its meaning? 
3. How are conceptual understandings mediated in university programs, and how do different settings, tools, and practices contribute to different degrees of appropriation of conceptual understanding?

4. How are conceptual understandings mediated in school settings, particularly when school goals and practices are different from those that prevail in universities, which serve as the initial formal setting for learning how to teach?

5. What are the effects of learning no unified concept; that is, when a university program lacks coherence among faculty with regard to an overarching concept to guide its approach to teacher education, what are the consequences for preservice teachers' understandings of how to teach?

6. At what point can a concept be mastered? If concept development requires extensive consideration across conceptual fields, is a preservice education program sufficient for enabling its students to develop and refine a concept? Or is it more likely that teachers will require sustained reinforcement and refinement of the concept as their careers mature in order to achieve a conceptual level of understanding?

\section{WHICH CONCEPT?}

Our research on the transition from teacher education program to the workforce included two programs (elementary, secondary English) at one university and one program (secondary English) at another. Among these programs, the elementary program had a single conceptual emphasis that was stressed throughout the five methods courses and the debriefing sessions attendant to the accompanying 150 hours of field experiences that the students took the semester before student teaching (see Cook et al., 2002; Smagorinsky, 1999b; Smagorinsky et al., in press). As part of the research design, the cohort of research participants from each of the three programs we studied met before and after student teaching to produce a group concept map that depicted their understanding of what is involved in teaching. One concept map produced by the elementary group corroborated what we had learned from individual interviews with students and faculty: that the program emphasized a single instructional concept, Piagetian constructivism, for its elementary education majors. This perspective was streamed throughout all elementary education courses taught within the curriculum and instruction department and also emphasized by faculty in the educational psychology department where the students took courses. 
As revealed through interviews and group meetings conducted with the seven participants from this program, this perspective included the tenets that (a) learning and learners are the focus, (b) students' activity is paramount, (c) the emphasis on learners suggests attention to student diversity, (d) appropriate materials include literature and writing, with meaning constructed by the learner, and (e) knowledge is connected. The university elementary education faculty shared a belief in Piagetian constructivism as outlined here, going so far as to use this orientation as a criterion when hiring new colleagues. Students were thus immersed in course work and school-based observations and teaching that had a constructivist emphasis. The students producing their concept map identified constructivism as the umbrella concept to guide all teaching decisions:

Student: [Constructivism] is your theory of teaching. I mean, that is like if you agree that kids have hands-on experience as opposed to you filling a cup. Everything you do [as a teacher] is going to have that here.

\section{Student: Constructivism.}

Researcher: So where is it - if it is so all-encompassing, where does it go?

Student: At the top with teacher and then the arrow pointing down.

Here the participants placed constructivism "at the top" of their drawing - that is, as the guiding principle for the kinds of instructional practices they identified during their discussion: learning centers, hands-on learning, cooperative group work, readers' theater, use of multicultural literature, and other practices that enable learners to construct personal knowledge and meaning.

Later we discuss the degree to which the faculty provided a uniform conception of constructivism in both their individual teaching and as a program faculty. Our question now concerns the conundrum faced by teacher educators when providing conceptions of teaching for their preservice teachers to appropriate (i.e., to grasp and make their own; see Wertsch, 1998). This problem is grounded in the age-old educational dilemma of whether to stress breadth or depth in covering a topic (e.g., Chicago Collaborative for Excellence in Teacher Preparation, 2001). Emphasizing breadth - covering many different conceptions of teaching without exploring any in depth - would have little potential for helping students to develop a strong concept, given the degree of reinforcement and experiential grounding necessary for one to make all of the necessary connections required for concept development. A stress on depth would 
provide more concentrated attention to fewer concepts, or perhaps to only one as in the case of the program that emphasized Piagetian constructivism.

Students themselves found the effort to provide a deep understanding of constructivism problematic. One teacher, Tracy, complained at one point that she learned constructivism at the expense of other approaches she might have learned: "They only taught us basically here at [the university] exactly like they said, well, you know they have to construct their own knowledge. That's the only thing, that's the only philosophy I believe I've learned.... Give me another philosophy I could actually learn and see if I like it as well, you know. I only learned [constructivism] here."

The alternative, presumably, would be to attend to other philosophies, conceptions, or approaches to teaching so that students could graduate with a greater array of choices from which to make instructional decisions. Teacher education programs may adopt any of a number of conceptual emphases in addition to those we studied: social justice (McDonald, 2003), cultural diversity (Ball, 2003), reflective practice (Schön, 1991), authentic assessment (Darling-Hammond, Ancess, \& Falk, 1995), phonemic awareness (Cunningham, 1989), and many others. While these perspectives are not necessarily exclusive of one another, each foregrounds particular conceptual issues that make it unique.

Adding concepts to the instructional mix might reduce the opportunity to grasp each. If a menu of concepts were presented in a survey approach, the strength of each would likely be further diluted. Buffet-style educational programs have often been criticized by educators (e.g., Powell, Farrar, \& Cohen, 1985) who feel that a brief sampling of many things results in a superficial knowledge more amenable to correct-answer testing than to the deep, dynamic, elaborate notion of the concept formulated by Vygotsky (1987). Teacher educators concerned with emphasizing concept development, then, need to consider the problem of which and how many concepts to emphasize within the relatively brief confines of a teacher education program.

\section{WHO OWNS THE CONCEPT?}

Most discussions of concept development, including Vygotsky's (1987), assume that a given concept has a more or less standard definition; that is, a concept such as constructivism, progressive education, whole language, or other educational emphasis has an official definition that one either appropriates or approximates in the form of a pseudoconcept or complex. Our work has identified considerable variation in how a concept is defined, even among those who purport to share a unified point of view with respect to the concept. For instance, in the program that emphasized constructivism, there were substantial discrepancies among the faculty in how constructivism took shape in their classes and practice. One participant, 
Tracy, revealed this variation in an interview just prior to her student teaching (see Cook et al., 2002):

Tracy: I don't think there is a consensus on the faculty either.

Researcher: Maybe they've all constructed their own.

Tracy: Their own knowledge. They've all constructed their own knowledge about it.

Researcher: Constructivism. (laughs)

Tracy: Constructed their own knowledge about it so no one really knows exactly what it is and I don't think every one will ever really know what it is, you know.... Everyone's version is totally different from everyone else's.

Tracy's view of the faculty's lack of agreement on the nature of constructivism was corroborated in interviews and concept map activities that involved other students in the program and was consistent with the protean character of constructivism across the field of education as described by Phillips (1995; cf. Cook et al., 2002).

We similarly found that teachers in the field understood concepts quite differently than did the university faculty with whom they shared the supervision of student teachers. In one of the secondary English programs we studied, the faculty consisted of two professors who team-taught and their cadre of teaching assistants and field experience supervisors. They provided a unified and consistent emphasis on student-centered teaching as they offered three campus-based courses and a semester-long practicum during the semester prior to student teaching. Furthermore, the program faculty cultivated and supported a team of mentor teachers who met year-round to discuss how best to apprentice university students into their lives as teachers. The university program thus used extensive field experiences and the mentor teacher group as a way for university-based students and faculty to stay connected to what was happening in the schools, with a shared pedagogical emphasis on the concept of student-centered instruction.

Yet what was embraced as student-centered instruction among the university faculty was occasionally at odds with the ways in which the mentor teachers practiced and consequently apprenticed their student teachers. One mentor teacher, Leila, seemed completely out of synch with the university program's student-centered philosophy (see Smagorinsky et al., in press). She restricted her student teacher's use of small group 
activities and other arrangements that produced noisy and potentially offtask interactions; had accumulated a wall full of file cabinets during her three decades of teaching that held innumerable worksheets, fixed-answer exams, and other accoutrements of what's generally regarded as teacherand-text-centered instruction; and was regarded by the university faculty and her student teacher Natalie as being perhaps the least consonant of 25 mentor teachers with the university program's philosophy.

Yet Leila described herself as student-centered, offering the following during an interview about her approach to teaching and to mentoring student teachers:

The students need to know, first of all, that I would not be here teaching if I did not care for them, that they are very important to me as human beings, first of all, and that I do care for them very much. And that's probably as much, as important as me trying to teach them subject [inaudible] or what's the plot of this story. And I try to convey that, I guess, in everything I do. It's changed over maybe the last ten years where I've put more emphasis on who they are more than I do on the subject material, simply because in 1990 we lost our teenage son in a car wreck. He was a senior here and that just really had a big effect on everything I do. That I want the students to enjoy and appreciate life. And I guess that comes through in my teaching. Because it did change a lot of things, how I looked at things.

Leila's great personal tragedy made her feel more attuned to the needs and life trajectories of her students and thus regard herself as more student centered. Yet observations revealed that she guided Natalie toward classroom processes and assessments that were highly restricted and text based, allowing for little personal connection between life and literature.

When considering this case, we began to ask, who owns the concept? The university faculty and members of the research team believed that Leila was not strongly student-centered, while Leila believed she was. Given the inconstant nature of concept definition we have observed, we wonder how difficult it is for students to appropriate a concept when the concepts are presented and practiced with such variety. Our concern remains that it is unclear who owns a concept, whether it's possible to assert an official definition of a concept, whether the different constraints and conditions of the university and public school settings result in different degrees of fidelity to any abstract system, and whether the conflicting environments of teaching practice result in conflicting efforts to practice the tenets of a concept.

We also see the ideological nature of praxis at work in this conflict. When a concept has ideological force, its practitioners may proceed with their 
work in such a way as to elevate their beliefs to a politically privileged status. With such forces at work, early-career teachers may feel torn amidst the political positioning that places schools and universities at odds with one another; that is, if university faculty feel that their station validates their notion of a concept, or if school-based faculty believe that their proximity to teaching realities affords their beliefs greater stature, then an early-career teacher who must answer to both may find his or her efforts to develop a concept for teaching compromised amidst these conflicting ideologies and claims to authoritative understandings of concepts.

Our consideration of this question, then, leads us to problematize Vygotsky's (1987) notion of the concept as representing an internally consistent set of traits in a categorization. We must pose the question: Internally consistent to whom? If one accepts the cultural argument that different cultures mediate activity and thinking toward particular ends based on the problems their environments provide for them to solve (Tulviste, 1991), then one must recognize that the different cultures of the university and school are likely to promote different goals and tools and thus different conceptions, even when using the same term. In Vygotsky's example in which the whale appears to be a fish until one looks more closely, an observer has a fairly concrete set of comparative objects with different, observable biological makeup (lungs vs. gills, hair vs. scales, etc.). Teaching practice is less amenable to such certain judgments, even if one accepts that science is more subjective and interpretive than many scientists claim (Latour \& Woolgar, 1986). If teacher educators accept the view that different cultures may legitimately view the same phenomenon in different ways (Smagorinsky, 1995), then making judgments about whose notion of a concept is most authoritative or internally consistent becomes problematic.

\section{HOW ARE CONCEPTS MEDIATED IN UNIVERSITY PROGRAMS?}

We described the problem of covering breadth or depth in preservice education courses. Prior research (e.g., Smagorinsky \& Whiting, 1995) suggests that there is great variation in how this question is resolved in the United States, ranging from courses that follow a survey approach that covers a range of issues cursorily, to courses in which students are asked to reflect on their experiences and observations to extract an approach inductively, to courses in which developing a theory of practice is stressed without great correspondence to classroom experience, to courses in which workshops are employed to stress a relatively small range of concepts to motivate instructional decisions. We next highlight some problems we found in the programs we studied that we believe interfered with students' efforts to develop what to our eyes were coherent conceptions of teaching. 
In the program with the constructivist emphasis, students exhibited difficulty in developing a concept for constructivist teaching. We attribute this difficulty in part to the lack of consistency in definition and practice among the program faculty. This variability was followed by inconsistency and indecision on the part of the students who presumably were being oriented to this approach. Tracy, for instance, when asked prior to student teaching, "What kind of teacher would you like to become?" responded:

Tracy: I guess I want to kind of be a constructivist teacher but I don't thoroughly know what constructivism is. I do know. You know, I do not exactly know what it is. No one has actually sat down and said, well, this is what it is....

Researcher: What do you think it is?

Tracy: Well, I mean, I believe, you know, the children do construct their own knowledge but it's not totally constructivism because you sit there and you say, well here is the materials that they can use to construct this knowledge .... I don't think anyone knows exactly what constructivism is .... And so I can't really say that I am a strong believer in constructivism because I don't know what it is.

It may be tempting to dismiss Tracy as simply dim and explain her inability to describe her program emphasis on the basis of weak candlepower. On the contrary, however, she was enrolled in her state's most competitive university and was viewed as among the brightest students in her class by faculty interviewed for the study. Furthermore, she was highly regarded in the schools in which she taught. Rather than locating the problem in Tracy, we use a Vygotskian perspective and look to mediators in the environment-particularly the variation in how the concept was defined by her university faculty - to explain her confusion, both in her ability to articulate the construct and in the inconsistencies we observed in her practice that led us to characterize her notion of constructivism as a pseudoconcept. In other words, to explain the seemingly conflicting way in which she understood constructivism, we look to conflicting means of mediation in the environment in which she learned to teach. We do so to infuse our analysis with the developmental dimension inherent to a Vygotskian approach, analyzing learning as a practice-mediated phenomenon that takes place over time in various activity settings and communities of practice such as university programs and schools.

The environmental conflicts included both competing definitions and inconsistencies between what her professors espoused and how they taught. Tracy described this contradiction during an interview: 
It was my first Language Arts [methods] class.... She'd say, well this is what, you know, this is how you should do it and here is the book, you know. This is a great lesson, blah, blah, blah, blah, blah, but read chapters 1 through 9 and you're going to have a test on it in two weeks and memorize this, this, this and this so you come down, you have a test and it's all listing. You know, list the six characteristics of blah, blah, blah and so you had to sit there and list and explain. And so we had pages and pages and pages of tests, so her tests did not follow her philosophy.

Tracy's remarks were echoed by other students we interviewed and observed from her program who spoke of the inconsistency between what was espoused and what was practiced by some of their program professors.

Tracy reveals how the conflicting environment of her initial learning, even though grounded heavily in classroom experience, contributed to the development of a pseudoconcept rather than a concept for the central approach to teaching emphasized in her program. Her case provides a key distinction between Piagetian and Vygotskian notions of constructivism. The Piagetian approach, at least as emphasized in her program, stressed the individual's ability to construct a personal understanding of the world through various experiences. With this assumption as their basis of belief, it made sense for each professor to conceive and practice constructivism in a unique way and for students to experience each and develop a personal understanding of constructivism through these experiences. From a Vygotskian perspective, at least as we understand it, this inconsistency served to obscure the motive of the setting, i.e., the overall cultural goal toward which activity is channeled (Leont'ev, 1981; Wertsch, 1985). We see, then, the presence of multiple goals and mediational means toward achieving those goals as serving, on the one hand, to provide learners with options and multiple pathways, and on the other hand, to diminish the possibilities of learning any one approach in a unified and coherent way.

\section{HOW ARE CONCEPTS MEDIATED IN SCHOOL SETTINGS?}

Often schools are identified as the villains when students leave their universities and enter the world of the classroom where different values and practices prevail. Borko and Eisenhart (1992), Ritchie and Wilson (1993), and others have argued that students learn progressive pedagogies in their preservice programs but then encounter in the schools an ethic more geared toward content coverage and control, thus diminishing the value placed on student-centered teaching methods learned in university programs. In this section we look at how concepts are mediated in school settings to see how university-based conceptions, no matter how well 
appropriated, fare once teachers enter the high-stakes evaluative environment of their jobs.

On some occasions in our research, participants such as Tracy left a teacher education program with what we believed to be a pseudoconcept. Without the concept being reinforced through either a shared terminology or compatible expectations, such teachers gravitated toward the prevailing norms held by the schools in which they taught in their first jobs. In these cases the formal vocabulary of the university was not employed in the school, with constructivist-like activities typically referred to by a term such as whole language, ultimately resulting in a conflation of the two in the teacher's account of her practice. At the same time the teacher's practice shifted along with the conceptions of teaching institutionalized among the school faculty. In Tracy's first job, for instance, she taught a combined kindergarten/first-grade class where she was expected to emphasize phonics so that her students could read and teachers in later grades could implement a whole language approach. Because Tracy had learned neither a vocabulary nor associated set of practices for teaching either phonics or whole language, and because teaching phonics often allowed for little constructivist activity on the part of learners, Tracy had few opportunities to reinforce her understanding of a constructivist pedagogy once she was a full-time teacher.

In Tracy's case the school provided a much easier transition than did the settings that we found awaited other teachers we studied. Andrea, for instance, a graduate of the secondary English program that emphasized student-centered instruction, entered her teacher education program very much a traditionalist but emerged with a good grasp of the studentcentered pedagogy advocated by her professors (see Smagorinsky et al., 2002). Her first job was in a large, diverse school district in which a strict, heavily scripted, centralized curriculum had been developed so that students in the less affluent parts of the district would receive the same education as the students in the wealthier areas. Andrea's job was in a prosperous community in which she hoped to use writing workshops and other student-centered activities to help students connect personally with their schoolwork. Yet she was thwarted by the curriculum in ways that prompted responses of acquiescence (acceptance of, compliance with, or submission to the curriculum), accommodation (a grudging effort to reconcile personal beliefs about teaching with the values of the curriculum), and resistance (opposition to the curriculum, either overtly or subversively).

Andrea described a typical compromise following a discussion of a poem that she conducted just prior to the administration of one of the district's periodic exams, which were tied to the centralized curriculum:

Andrea: Sometimes it can get sort of bad because the county questions will ask a question and will give an answer that I don't necessarily 
agree with. But in the course of the instruction I will attempt to purposely convince them all to believe that this would be the answer to this kind of question.

Researcher: Oh, really? Could you give me an example of that?

Andrea: I wish I had my actual assessment folder with me because there were several of them last time. I'm trying to think, what was the - they asked - there was a question on-it was a poem also last time. It was, "Ithaca" was the title of it. It was actually part of our "Odyssey" unit and the poem talked about Odysseus's journey and one of the questions asked what values - or what themes does this poem emphasize. And the answer that they wanted you to choose from the multiple choice questions was Odysseus's-or the importance of home and family. And - but in the process of reading the poem, the poem really talked a lot more about the value of the journey. And so I thought - oh, I really hated that that was the answer to that question. But in the course of the discussion I attempted to convince the students that were they ever asked that, they should answer that it was the importance of home and family.

Researcher: Really?

Andrea: Yes. Pretty pathetic, I know. Sorry. What else am I supposed to do?

We viewed Andrea's decision as an act of accommodation; that is, she surrendered her own goals to the standard of the curriculum, albeit regretfully. We found that continual accommodation of beliefs to the values of the school or district curriculum left Andrea and teachers in similarly restrictive settings frustrated with their efforts to teach in ways that they regarded as appropriate and effective and limited their opportunities to enact any kind of praxis in their work.

A final example comes from Sharon, another participant from the constructivist elementary program who did her student teaching in a classroom where the values were diametrically opposed to those of her university program (see Smagorinsky et al., in press). Her mentor teacher, who also served as the school's de facto assistant principal and thus carried considerable weight as an authority within the school, described her own teaching during interviews as predicated on learning correct form in language. She approached her mentorship of Sharon with the same authoritarian air as she did her students, using what we characterized as a mimetic approach to apprenticing Sharon (Jackson, 1986). When discussing 
her student teaching experience during the concept map activity that followed her student teaching, she said to the other students in her cohort:

Sharon: She was head teacher. She is boss. (group laughter and remarks) Well, I'm serious. There is no way I would dare tell her she is doing something wrong. You've got to be kidding!... My teacher had taught for like 19 years in the same room so I didn't dare even say that her bulletin boards looked crooked or anything.... Even if I had had the freedom to try out a lot of things, my 3rd grade, these kids didn't respond well to constructive learning. They went crazy. Because then if you had like open discussion or if you were having something that was not their norm or they raised their hand to respond, they just went berserk.... They couldn't handle not having their structure they were so used to.

Penny: Yeah, see I found out even in the 1st grade level there was just so much structure in the poor kids' lives that they had been in kindergarten and transition and now in 1st grade. I mean that's two or three years they're getting this really traditional structure stuff and so when I would come in and try to do creative kinds of things, they are like, "I don't know what you're trying to get at." I'm like well use your imagination and like [inaudible]. That was real stressful.

Penny also did her student teaching at the same school as Sharon and found herself under many of the same constrictions (see Smagorinsky, 1999b). Their remarks - substantiated by the observations we made of their teaching, our interviews with their university supervisors, and our interviews with their mentor teachers - suggest that a concept, no matter how coherently learned, may be at odds with the expectations of particular schools or subparts therein.

Again, we look to the settings of teaching to consider the problem of concept development in early-career teachers. Assessments of teachers in schools can have dramatic consequences, with contract extensions, tenure, and other means of security at risk when teachers defy the motive of the school setting. The mediational context, then, may promote activity and thinking, and thus concept development, toward institutional goals - highstakes test scores, standard behaviors and outcomes, orthodox interpretations of texts, etc. - that run counter to the goals emphasized in universities. While some attribute traits such as neurosis to teachers who work within conflicting environments (e.g., Emig, 1971), we see the environments themselves and their conflicting goals and demands as contributing to teachers' decisions and the conceptions that inform them. The mediational contexts of schools, then, which are responsive to a host of tensions that do 
not affect thinking in universities, can contribute to teachers' thinking and knowledge in ways that make the project of university-based teacher education both challenging and frustrating.

\section{WHAT ARE THE EFFECTS OF LEARNING NO UNIFIED CONCEPT?}

Thus far we have reviewed cases from teachers enrolled in two programs that offered coordinated blocks of courses designed to focus on a single conception of teaching. Not all programs dedicate such faculty resources to the teaching of preservice teachers. It is quite common, for instance, for secondary education preservice programs to provide extensive coursework in the content area of preparation; courses in foundations, educational psychology, and other prerequisite fields; and finally, a single methods course in the teacher's field (or, in institutions with fewer resources dedicated to teacher preparation, a general methods course that enrolls students from all areas of preparation) (Marshall \& Smith, 1997).

The second English education program in our research was such a site. Given the lack of coordination among the English department, the educational psychology department, the foundations department, and the English Education program, the students experienced a conceptually haphazard teacher education preparation. Because students took the same courses in different semesters from different faculty (including an array of teaching assistants), they arrived at the methods class with diverse understandings and models of how to teach effectively. The methods class was then invested with the task of coordinating these various experiences into a conception of teaching that accounted for all of the various strands under the banner of English: literature, writing, language, media, and other aspects of literature-based language arts education. This coordination was expected to occur in a single class taken during the semester prior to student teaching, although uneven student advisement often placed students in this class at earlier points of their education sequence.

Participants from this program all came out with different emphases. While students in the elementary program at the same university all espoused constructivism, however unevenly, we found no consistent terms coming from the secondary English cohort to characterize their approach to teaching. Indeed, the emphases they claimed were often difficult to locate in their teaching, leading us to regard this group as having no unified conception of teaching. As we have done with other cohorts we have studied, we attribute this phenomenon to environmental factors rather than cognitive deficiencies on the part of the preservice teachers. Given the structural fragmentation (Zeichner \& Gore, 1990) of the program - that is, the absence of a sustained, consistent focus on a pedagogical approach or teaching philosophy - we find it quite understandable that graduates of this 
program claimed not only different conceptions but inconsistencies among these conceptions.

Those who emerged from this program tended to learn their conceptions of teaching in the sites of their early-career teaching experiences. Rather than seeing the university program as their conceptual home base (Smagorinsky, 2002) - the community of practice to which they return for conceptual understanding and reinforcement - they tended to gravitate quickly to the norms and practices of their student teaching and first job sites which served as the settings of consequence-bearing, high-stakes assessments of their teaching. For some teachers this orientation worked well, such as when they came under the guidance of skillful and conscientious mentor teachers or were provided with useful curriculum materials such as the Pacesetter curriculum, ${ }^{1}$ as did one teacher we observed (cf. Grossman, Thompson, \& Valencia, 2001). For others the institutional norms were more at odds with the emphasis of the university methods class, as was the case of Leigh, whose eighth-grade teaching assignment stressed preparation for the state writing test, which used a rubric rewarding writers who could produce five-paragraph themes (see Johnson et al., in press). This form, while widely practiced in schools, has been much-reviled by many in the field of composition (e.g., Hillocks, 2002) for its tendency to emphasize and reward form over content.

Wideen, Mayer-Smith, and Moon (1998) regard education programs such as the one Leigh attended as "a patina of beliefs layered over a lifetime of learning" whose effects are so limited that "When confronted with the realities of the classroom, these beginning teachers reverted to their deeper belief system" (p. 158; cf. Rust, 1994). This process was at work with Leigh, who had achieved success as a student by writing five-paragraph themes, had gone through a structurally fragmented teacher education program that left her without a guiding concept to inform her teaching decisions, and had entered a teaching environment in which her colleagues stressed the importance of teaching to the state writing test.

Structurally fragmented programs such as the one from which Leigh graduated, which in our experience are legion, thus appear ill equipped to teach students concepts for their teaching. Without continual reinforcement over time and settings, a concept does not have an opportunity to mature beyond its rudimentary stages. It thus yields easily to the values and accompanying practices that govern beliefs about good teaching that prevail in schools, which ultimately provide the evaluative context for one's teaching. We found graduates of this structurally fragmented program to provide the least evidence of having a unifying concept among the participants in our research. While other programs produced evidence of helping preservice teachers to develop at least a complex or pseudoconcept to work reciprocally with what they learned through teaching experience 
and school-based observation, the structurally fragmented program appeared far too diffuse to have a conceptual impact that cohered and matured beyond the course work.

\section{AT WHAT POINT CAN A CONCEPT BE MASTERED?}

We next acknowledge the likelihood that prospective teachers cannot develop mastery of a concept in the short time during which they are enrolled in a university teacher education program. Participants in our research gave evidence that they had appropriated the conceptual underpinnings of a pedagogical practice such as student-centered instruction but were not always able to implement such practices in their own classrooms. In some cases such as Andrea's, this lack of implementation resulted from the constraints of the curriculum; in other cases, the participants found the program's conception of teaching to be at odds with their own motivations to teach and abandoned them when beyond the evaluative influence of the university program.

While they could often critique teachers they observed in the field according to the principles of the central concept stressed in their programs, participants in our research had greater difficulty planning and carrying out instruction that achieved the unity inherent to a concept. Wertsch's (1998) distinction between appropriation and mastery is useful in considering this problem. He describes appropriation as the process of "taking something that belongs to others and making it one's own" (p. 53). Cultural tools, he argues, tend to be appropriated with difficulty and unevenness; the path to concept development is a twisting one indeed. One might appropriate a tool yet resist or reject it, as with those participants in our research who appeared to understand the principles of the concept stressed in the programs yet turned to other approaches when teaching.

Wertsch (1998) argues that mastery requires this greater commitment to using a concept and its attendant tools effectively, a process that most likely would take years of practice to achieve (cf. Grossman et al., 1999). Our research did not follow our participants long enough to discern the extent to which they refined their understanding of the pedagogical tools with which they were presumed to begin and sustain their teaching careers. Our research suggests that without extending one's engagement with a community of practice, a teacher's ability to refine a concept toward maturity is greatly compromised.

\section{DISCUSSION}

As teacher educators, our interests following this research concern the kinds of concepts prospective teachers learn while in university programs in terms 
of both the teaching approach they develop and the degree (concept, pseudoconcept, complex) to which they develop it. We see concept development among early-career teachers as a worthwhile pedagogical goal for teacher educators, albeit a difficult one to realize. Given this goal, we see a set of considerations following from our effort to read across the cases of the participants in our research.

\section{THEORY, PRACTICE, AND CONCEPTS}

We critiqued the idea that the official definition of a concept resides at the university. Concepts, many university faculty believe, are conveyed through course texts and the faculty member's means of instruction, then tested or modified through observations and experiences in schools. Variations on the concept's definition offered in school settings are regarded as idiosyncratic, compromised by accommodation to local problems, or downright erroneous. We see this hierarchical view to be unfortunate and inadequately focused on the valorization of the university as the seat of authoritative ideas. If integrating conceptual fields is essential to the development of a concept, then both the rules learned through formal instruction and abstraction and the experiential lessons learned through practice ought to be interdependent. We see the need for university faculty to treat the experiences of school-based teachers with sufficient respect to warrant inclusion of their perspectives in the development and articulation of concepts. It is critical, we feel, to engage in discourse and practice that do not bifurcate the two but rather integrate understandings from conceptual fields into a coherent definition of a concept.

The necessary shift in discourse would, in our vision, come through the abandonment of the theory-practice binary and adoption of the terminology of concept development. If word and world are indeed intertwined as argued by Freire (1972), then this change in discourse could be accompanied by change in practice. Rather than viewing theory as being under the authority of the university and practice as being the domain of the school, educators could treat the conceptual fields as mutually dependent and regard concepts as being in an ongoing state of reconsideration and redefinition.

\section{ADDITIONAL FACTORS IN THE DEVELOPMENT OF TEACHERS' CONCEPTIONS}

One might argue that a teacher's apprenticeship of observation-those experiences about teaching gained through being a student (Lortie, 1975) - will suffice for the interplay of spontaneous and scientific concepts. Yet one's apprenticeship of observation alone is likely tied to the learner's 
own cultural experiences and is not necessarily able to be extrapolated to the experiences of diverse learners, especially those who are not what Lortie calls identifiers (those who believe in the institution of school and its practices) or what Eckert (1989) calls jocks (those identifiers, usually from the upper and middle social classes, who uphold and maintain school values, especially its activities): those who like and believe in school the way it is and are more likely to return to them as teachers. We do not make this observation to dismiss the importance of considering one's own educational experiences in the development of a conception of teaching. Rather, we wish to qualify this importance and say that such experiences ought to be the subject of informed reflection - that is, rumination couched in an understanding of issues of culture.

We do not wish to place too much importance on the faculty's role in students' development of concepts. We are well aware that students may reject the concepts emphasized by university faculty. One of our research participants, an African American male who exited student teaching before completing the term required for certification, resisted his professors' emphasis on student-centered instruction in the progressive tradition, arguing from exposure to other texts (e.g., Delpit, 1995) that such instruction potentially served students of color poorly. He thus aligned himself with a different conceptual perspective and concomitant discourse stream that enabled him to critique his professors' orthodox views. Another student from the same program abandoned any notion of student-centered instruction once settled at her first job, turning readily to whatever planning materials relieved her of the burden of instructional planning and as a result providing her students with a series of worksheets tied to the course readings. We see, then, the setting of teacher education serving as but one arena of influence on early-career teachers' concept development, albeit a critical one and the one most available to teacher educators to affect. We view the idiosyncratic trajectories of prospective teachers such as the ones we have just described not as signs of simple caprice but as indicators of students for whom conceptions of teaching derived from other sources had greater appeal and relevance.

\section{QUALITIES OF EFFECTIVE UNIVERSITY-BASED TEACHER EDUCATION PROGRAMS}

Our study of teacher education programs, while limited to three structures, suggests that some are more effective than others in helping prospective teachers to develop pedagogical concepts. We next outline the qualities that we feel contributed most to students' ability to develop strong conceptions of teaching. 
We argued that, ideally and to the greatest extent possible, attention to an overarching concept for teaching should serve as the means of unifying the coursework in teacher education programs. If, as we believe, a program ought to be programmatic - that is, systematically orchestrated toward a limited set of goals - then an overarching concept can inform the ways in which the various courses within the program are conceived and taught and offered in conjunction with experiences in the field. A number of analysts of curriculum have argued that an overarching theme (Applebee, 1996) or overall instructional coherence (Newmann, Smith, Allensworth, \& Bryk, 2001) leads to greater student achievement and synthesis of instruction. In Applebee's notion of curriculum as conversation, for instance, a curriculum provides the forum for extended conversations (i.e., talk that extends over time, as opposed to the specific episodes of talk he terms discussion). This extended conversation spirals in Bruner's (1960) sense in that it engages participants in an ongoing exploration and extension of a theme or concept as it is mediated through a variety of topics.

We see Applebee's (1996) views regarding the K-12 curriculum as being relevant to our beliefs regarding concept development among preservice and early-career teachers: University teacher education programs create a more fertile setting for preservice teachers' concept development when they provide a coherent curriculum in which a conception of teaching is emphasized over time, considered and extended in terms of a variety of questions, and grounded in school-based experiences. Were teacher educators to approach curriculum and instruction with such a goal, they might minimize the problems of structural fragmentation noted by Zeichner and Gore (1990) and observed in our research, helping students integrate university-based instruction with school-based teaching and observing purposefully and cohesively.

We have seen, however, that achieving this unity is difficult, and we recognize that for some education faculty it might be undesirable. The principle of academic freedom, for instance, makes any individual faculty member's allegiance to group goals tenuous; some faculty may dispute the majority view and work to critique the resident orthodoxy from a different perspective. Even on occasions when faculty agree on a concept, as in the case in the program emphasizing constructivism, individual variations in their interpretation and presentation of the concept - even when each has internal consistency - may contribute to fragmentation among students in their own effort to develop the concept. As we noted, adherents of the sort of Piagetian constructivism observed in the elementary program in our study might celebrate this individual construction of concepts. The students in the program, however, found it frustrating and difficult to put into practice.

Additionally, our research has focused on large programs with abundant faculty resources dedicated to preservice teacher education. Universities 
with smaller education faculty and fewer resources might have even greater difficulty achieving the articulation necessary for the reinforcement of a concept across courses in a program and throughout field experiences, especially if instructional responsibilities are dispersed across campus units that have little contact with one another. In contrast to reaching the ideal of helping prospective teachers develop concepts related to their instruction, university programs might more predictably graduate students who are likely to develop pseudoconcepts or complexes.

We do not aim to prescribe a particular way to teach concepts but rather to argue for the importance of emphasizing concepts through whatever avenue helps students to integrate their spontaneous and scientific conceptual fields. In the programs we studied, we saw the best potential for this integration coming from continual reinforcement of a concept across a series of deliberately integrated courses, offered in blocks of instruction by faculty who shared general agreement on the concept emphasized. This programmatic offering of courses was experienced by students in cohort groups so that they could engage in the type of ongoing conversations envisioned by Applebee (1996). In contrast, the program with the greatest structural fragmentation produced students who, when asked to identify the ideal teacher during interviews and concept map activities, came up with different and apparently idiosyncratic answers.

This differential response in itself is not necessarily a problem. The problem came when these teachers entered schools: Given the fragmentation of their responses and conceptual sketchiness of their beliefs, they tended to adapt to whatever instructional approach they were exposed to in the school setting. Those whose mentorship or curriculum provided them only with cookie-cutter curricula - teacher manuals or formulas such as the five-paragraph theme - had few discriminating tools available to critique or modify instruction against some conception of teaching.

\section{EXTENDING CONCPETS FROM A CONCEPTUAL HOME BASE}

We used the term conceptual home base to describe a community of practice whose ideas are powerful enough to inspire ideological loyalty and enduring, if ever-developing, beliefs about teaching. As we have argued, the university may serve as practitioners' conceptual home base if it effectively teaches conceptions that its graduates find powerful and useful in the classroom. One way to help sustain these conceptions once the university program loses its imperative in its graduates' lives is to create settings that enable ongoing contact and dialogue. As Sarason (1972) argued, the creation of new settings is typically undertaken with such great hope that their architects overlook the myriad problems that may develop during their enactment. Our view of settings for inservice professional 
development, then, is tempered by the understanding that they are not panaceas but as problematic as any social effort.

We next describe some ways in which university teacher education programs have extended opportunities to practicing teachers to continue their formal thinking about conceptions of teaching.

\section{Affiliations With National Efforts}

National organizations such as the National Council of Teachers of English and their state affiliates provide umbrella structures help keep teachers apprised of developments in the field, providing such vehicles as publications, discussion networks, and conferences that help stimulate and extend conversations. Similarly, the National Writing Project provides a forum for initiation and renewal for practicing teachers interested in improving their effectiveness as writing teachers. Efforts such as Project S.T.A.R.T. (Cochran-Smith \& Lytle, 1993) seek to link the Philadelphia Writing Project with local preservice programs that emphasize action research, thus establishing a relationship at the beginning of teachers' careers that they can maintain throughout their teaching.

\section{Induction Programs}

Many feel that some form of induction program - that is, continued support of teachers once they enter the workforce for a period of several years - will help to offset the problem we observed in these teachers. Undoubtedly such efforts have potential. The American Federation of Teachers (2000) recommends that all teachers participate in some sort of induction in their first few years of teaching as part of a professional development continuum. They argue that in contrast to the United States, "other countries with high achieving school systems induct new teachers into the profession through clinical, real-world training processes ... by which inductees develop and perfect their teaching skills under the mentorship of more experienced and skilled colleagues" (p. 32).

Such initiatives ought to be explored, keeping in mind Sarason's (1972) caution about the pitfalls involved in creating new settings. Induction programs assume that people who share the same conception of teaching are available to provide continuity from university to workplace. Our research suggests that this cadre of like-minded professionals may be harder to assemble than it appears. Leila, for instance, was part of a mentor teacher collective that met frequently with one another and the university faculty and presumably shared an evolving understanding of the concept of student-centered teaching. Even such a well-indoctrinated teacher, 
however, engaged in practice that appeared from our perspective to be authoritarian (if gently) and to be centered on orthodox readings of prescribed texts, an approach greatly at odds with the campus-based perspective. We wonder, then, how effectively an induction program can assemble a support group that provides the kind of continuity that presumably is necessary for concept formation to proceed in rich and useful ways.

\section{Small Teacher Collaboratives}

Action research collaboratives have been shown to have beneficial effects not only on what teachers learn about research but on their development of a sense of community as innovative teachers (O'Donnell-Allen, 2001). While not necessarily tied to university teacher education programs, they can be sponsored by universities (e.g., Project S.T.A.R.T.), writing project affiliates, or grants obtained by university or school-based faculty members.

\section{In-Service Programs}

Graham, Hudson-Ross, and McWhorter (1997) describe how a subset of faculty within a large university program set up a network of teachers from a variety of local schools. The network provides a forum for professional development for the teachers; enables the university faculty to stay closely in touch with their concerns, priorities, needs, and interests; gives the teachers a role in the development of the teacher education program; helps sustain mutually respectful and collegial relationships between schools and university; and, with the teachers serving as cooperating teachers for the program's preservice teachers, provides reasonably good alignment between campus and school for these faculty members' student teachers.

\section{Outreach Efforts and Partnerships}

Teacher education programs can establish partnerships that promote reciprocal relationships between university and K-12 faculty. The Center on English Learning and Achievement's Partnership for Literacy, for instance, is designed to work with teachers to implement and refine research-based approaches to curriculum and instruction. The program is problem based and involves teachers in activity with the goal of effecting authentic educational change. The instructional activities are tied to teachers' ongoing work and stresses both conceptual and practical tools so that teachers may deepen their understanding of the ways in which they 
teach while broadening their repertoires of instructional techniques. The partnership provides all stakeholders with a professional discourse community within which they debate, examine their assumptions, explore existing practice, and formulate new possibilities for what education might be. Finally, the partnership encourages teachers to reflect on their own practice and use this reflection as an important part of their own progress in their career development.

\section{Electronic Discussions}

Electronic discussion lists are increasingly accessible to teachers and can serve either very general levels of discussion (e.g., NCTE-talk) or highly specialized discussions (e.g., the GLESOL-L network for gay, lesbian, bisexual teachers of speakers of other languages). While electronic discussion lists can be onerous for teachers with high demands at work, they can also provide communities of practice when such support is not available in their schools.

\section{CONCLUSION}

We borrowed Vygotsky's (1987) metaphor of the twisting path to characterize developing a conception of learning to teach. This path, initially charted for many early-career teachers in university programs, may end up taking students in unlikely directions or other paths altogether. Our effort with this essay is to argue for greater attention to this conceptual path and its constituent materials and experiences and make the case for starting their journey with the clearest map and most advantageous accoutrements available.

This research was supported by a grant from the Office of Educational Research and Improvement to the Center on English Learning and Achievement (CELA). Earlier versions of this paper were presented at the Fifth Congress of the International Society for Cultural Research and Activity Theory in Amsterdam, at the Conference on English Education workshop at the 2002 Fall Convention of the National Council of Teachers of English, at the Center for Language Acquisition at Penn State University, at the 2003 Miami CHAT symposium at Florida International University, and at the 2003 conference of the American Educational Research Association; thanks to those in attendance at each presentation for their feedback. Special thanks are due to the teachers whose generous contributions of time have enabled us to do this work; to Jane Agee, Pam Grossman, and Sheila Valencia of CELA for their contributions to the research design and insights regarding the collection, analysis, and interpretation of the data; to Alfredo Artiles, Richard Beach, Brad Belbas, Judith Langer, Melanie Sperling, and Phillip White for their insightful readings of earlier drafts of the paper; and to the editors and external reviewers of TCR for their considerable time and attention in critiquing the manuscript 
Notes

1 Not all view the Pacesetter curriculum favorably; see, e.g., Daniels (1994).

\section{References}

American Federation of Teachers. (2000, April). Building a profession: Strengthening teacher preparation and induction (Report of the K-12 Teacher Education Task Force). Washington, DC: Author.

Applebee, A. N. (1993). Literature in the secondary school: Studies of curriculum and instruction in the United States (NCTE Research Report No. 25). Urbana, IL: National Council of Teachers of English.

Applebee, A. N. (1996). Curriculum as conversation: Transforming traditions of teaching and learning. Chicago: University of Chicago Press.

Association for Computing Machinery. (1997). The Paris Kanellakis theory and practice award. Retrieved June 19, 2003, from http://www.acm.org/awards/kan.html

Baldassarre, V. A. (1997). Frameworks to draw upon in designing programmes for beginning teacher in Europe. Comenius project 71599. Brussels: Association for Teacher Education in Europe.

Ball, A. (2003, April). Ideological becoming: Early-career teachers' developing conception of teaching diverse student populations. Paper presented at the annual meeting of the American Educational Research Association, Chicago.

Ballenger, C. (1999). Teaching other people's children: Literacy and learning in a bilingual classroom. New York: Teachers College Press.

Bennett, W. J. (Ed.). (1993). The book of virtues : A treasury of great moral stories. New York: Simon \& Schuster.

Beyer, L. E. (Ed.). (1996). Creating democratic classrooms: The struggle to integrate theory and practice. New York: Teachers College Press.

Bruner, J. (1960). The process of education, Cambridge, MA: Harvard University Press.

Bullough, R. Jr. (1989). First-year teacher: A case study. New York: Teachers College Press.

Carr, W., \& Kemmis, S. (1986). Becoming critical: Education, knowledge and action research. New York: Falmer.

Chicago Collaborative for Excellence in Teacher Preparation. (2001). Third annual symposium series on excellence in teaching undergraduate science and mathematics: National and Chicago perspectives. Retrieved June 19, 2003, from http://www.math.uic.edu/IMSE/CETP/symposium2001.html

Cochran-Smith, M., \& Lytle, S. L. (1993). Inside/outside: Teacher research and knowledge. New York: Teachers College Press.

Cohen, D. K. (1988). Teaching practice: Plus que ça change .... In P. W. Jackson (Ed.), Contributing to educational change: Perspectives on research and practice (pp. 27-84). Berkeley, CA: McCutchan.

Cole, M. (1996). Cultural psychology: A once and future discipline. Cambridge, MA: Harvard University Press.

Colorado Writing Tutors Conference. (2000, February). Theory and practice in the writing center (or theory versus practice?). Lakewood, CO: Author. Retrieved June 19, 2003, http:// www.ppcc.cccoes.edu/owl/Call2002.htm

Cook, L. S., Smagorinsky, P., Fry, P. G., Konopak, B., \& Moore, C. (2002). Problems in developing a constructivist approach to teaching: One teacher's transition from teacher preparation to teaching. The Elementary School Journal, 102, 389-413.

Cunningham, A. E. (1989). Phonemic awareness: The development of early reading competency. Reading Research Quarterly, 24, 471-472. 
Daniels, H. A. (1994). Pacesetter English: Let them eat standards. English Journal, 83(7), $44-49$.

Darling-Hammond, L., Ancess, J., \& Falk, F. (1995). Authentic assessment in action: Studies of schools and students at work. New York: Teachers College Press.

Delpit, L. D. (1995). Other people's children: Cultural conflict in the classroom. New York: New Press.

Dyson, A. H. (1990). Weaving possibilities: Rethinking metaphors for early literacy development. The Reading Teacher, 44, 202-213.

Eckert, P. (1989). Jocks and burnouts: Social categories and identity in high school. New York: Teachers College Press.

Emig, J. (1971). The composing processes of twelfth graders (NCTE Research Report 13). Urbana, IL: National Council of Teachers of English.

ERIC Clearinghouse on Reading English and Communication. (1995). From theory to practice: Classroom application of outcome-based education. Bloomington, IN: Author Retrieved June 19, 2003, from http://www.ed.gov/databases/ERIC_Digests/ed377512.html

Feiman-Nemser, S., \& Buchmann, M. (1985). Pitfalls of experience in teacher preparation. Teachers College Record, 87, 53-65.

Freire, P. (1972). Pedagogy of the oppressed. New York: Continuum.

Gallagher, P. (1996). Making education work. Elements, 2. Retrieved June 19, 2003, from http:// www.ul.ie/ childsp/Elements/issue2/gallag.html

Graham, P., Hudson-Ross, S., \& McWhorter, P. (1997). Building nets: Evolution of a collaborative inquiry community within a high school English teacher education program. English Education, 29, 91-129.

Grisham, D. L., \& Brink, B. (2000). Model classrooms: A theory to practice link for preservice teacher education. Vancouver, WA: Southwest Washington Educational Partnership Retrieved June 19, 2003, from http://www.vancouver.wsu.edu/programs/edu/swep/Model Classroom.pdf

Grossman, P. L., Smagorinsky, P., \& Valencia, S. (1999). Appropriating tools for teaching English: A theoretical framework for research on learning to teach. American Journal of Education, 108, 1-29.

Grossman, P. L., Thompson, C., \& Valencia, S. (2001). District policy and beginning teachers: Where the twain shall meet. Seattle: Center for the Study of Teaching and Policy, University of Washington.

Hirsch, E. D. (1987). Cultural literacy: What every American needs to know. Boston: Houghton Mifflin.

Jackson, P. W. (1986). The practice of teaching. New York: Teachers College Press.

Jackson, P. W. (1992). Untaught lessons. New York: Teachers College Press.

Johnson, T. S., Smagorinsky, P., Thompson, L., \& Fry, P. G. (in press). Learning to teach the fiveparagraph theme. Research in the Teaching of English.

Kallos, D. (1999). Recent changes in Swedish teacher education. TNTEE Publications, 2, $165-174$.

Kearsley, G. (1994-2001). Explorations in learning \& instruction: The theory into practice database. Jacksonville State University Encyclopedia of Psychology. Retrieved June 19, 2003, from http://tip.psychology.org/

Latour, B., \& Woolgar, S. (1986). Laboratory life: The construction of scientific facts. Princeton, NJ: Princeton University Press.

Lave, J., \& Wenger, E. (1991). Situated learning: Legitimate peripheral participation. New York: Cambridge University Press.

Leont'ev, A. N. (1981). Problems of the development of mind. Moscow: Progress Publishers.

Lortie, D. C. (1975). Schoolteacher: A sociological study. Chicago: University of Chicago Press.

Luria, A. R. (1976). Cognitive development: Its cultural and social foundations. Cambridge, MA: Harvard University Press. 
MacLean, M. S., \& Mohr, M. M. (1999). Teacher-researchers at work. Berkeley, CA: The National Writing Project.

Marshall, J. D., \& Smith, J. (1997). Teaching as we're taught: The university's role in the education of English teachers. English Education, 29, 246-271.

McDonald, M. (2003, April). Building a plane while flying it: Adventures in the integration of social justice in teacher education. Paper presented at the annual meeting of the American Educational Research Association, Chicago.

Merriam-Webster. (1996). Merriam-Webster's collegiate dictionary, electronic edition (Version 1.5). Springfield, MA: Author.

Newmann, F. M., Smith, B., Allensworth, E., \& Bryk, A. S. (2001). Instruction program coherence: What it is and why it should guide school improvement policy. Educational Evaluation and Policy Analysis, 23(4), 297.

Noddings, N. (1993). The challenge to care in schools. New York: Teachers College Press.

O'Donnell-Allen, C. (2001). Teaching with a questioning mind: The development of a teacher research group into a discourse community. Research in the Teaching of English, 36, $161-211$.

Phillips, D. C. (1995). The good, the bad, and the ugly: The many faces of constructivism. Educational Researcher, 24(7), 5-12.

Postman, N., \& Weingartner, C. (1987). Teaching as a subversive activity. New York: Dell.

Powell, A. G., Farrar, E., \& Cohen, D. K. (1985). The shopping mall high school: Winners and losers in the educational marketplace. Boston: Houghton Mifflin.

Sanford, B. (1999). Becoming members of the math club: First graders as emergent mathematical thinkers. In M. MacLean \& M. Mohr (Eds.), Teacher-researchers at work (pp. 232-242). Berkeley, CA: The National Writing Project.

Sarason, S. B. (1972). The creation of settings and the future societies. San Francisco: Jossey-Bass.

Schön, D. A. (Ed.). (1991). The reflective turn: Case studies in and on educational practice. New York: Teachers College Press.

Scribner, S., \& Cole, M. (1981). The psychology of literacy. Cambridge, MA: Harvard University Press.

Searle, D. (1984). Scaffolding: Who's building whose building? Language Arts, 61, $480-483$.

Smagorinsky, P. (1995). The social construction of data: Methodological problems of investigating learning in the zone of proximal development. Review of Educational Research, $65,191-212$.

Smagorinsky, P. (1999a). Standards revisited: The importance of being there. English Journal, 88 (4), 82-88.

Smagorinsky, P. (1999b). Time to teach. English Education, 32, 50-73.

Smagorinsky, P. (2002). Teaching English through principled practice. Upper Saddle River, NJ: Merrill/Prentice Hall.

Smagorinsky, P., Cook, L. S., Jackson, A. Y., Moore, C., \& Fry, P. G. (in press). Tensions in learning to teach: Accommodation and the development of a teaching identity. Journal of Teacher Education.

Smagorinsky, P., Lakly, A., \& Johnson, T. S. (2002). Acquiescence, accommodation, and resistance in learning to teach within a prescribed curriculum. English Education, 34, 187-213.

Smagorinsky, P., \& O'Donnell-Allen, C. (2000). Idiocultural diversity in small groups: The role of the relational framework in collaborative learning. In C. D. Lee \& P. Smagorinsky (Eds.), Vygotskian perspectives on literacy research: Constructing meaning through collaborative inquiry (pp. 165-190). New York: Cambridge University Press.

Smagorinsky, P., \& Whiting, M. E. (1995). How English teachers get taught: Methods of teaching the methods class. Urbana, IL: Conference on English Education and National Council of Teachers of English. 
Smith, M. K. (1999). Praxis. The informal education homepage. Retrieved June 19, 2003, from http://www.infed.org/biblio/b-praxis.htm

Stephens, D., Boldt, G., Clark, C., Gaffney, J., Shelton, J., Story, J., \& Weinzierl, J. (1999). Learning (about learning) from four teachers. Research in the Teaching of English, 34, 532-565.

Voutira, E. (1996, April). The "It's too theoretical" syndrome. Forced Migration Review, 21. Retrieved June 19, 2003, from http://www.fmreview.org/rpn211.htm

Vygotsky, L. S. (1987). Thinking and speech. In R. Rieber \& A. Carton (Eds.) and N. Minick (Trans.), Collected works (vol. 1, pp. 39-285). New York: Plenum.

Weaver, M. (1998). The feminist bridges project: Bridging feminist theory and practice. Wooster, OH: The College of Wooster Department of Political Science Retrieved June 19, 2003, from http://www.wooster.edu/polisci/mw/235.98.projects.html

Wertsch, J. V. (1981). The concept of activity in Soviet psychology: An introduction. In J. V. Wertsch (Ed. \& Trans.), The concept of activity in Soviet psychology (pp. 3-36). Armonk, NY: Sharpe.

Wertsch, J. V. (1985). Vygotsky and the social formation of mind. Cambridge, MA: Harvard University Press.

Wertsch, J. V. (1991). Voices of the mind: A sociocultural approach to mediated action. Cambridge, MA: Harvard University Press.

Wertsch, J. V. (1998). Mind as action. New York: Oxford University Press.

Wertsch, J. V. (2000). Vygotsky's two minds on the nature of meaning. In C. D. Lee \& P. Smagorinsky (Eds.), Vygotskian perspectives on literacy research: Constructing meaning through collaborative inquiry (pp. 19-30). New York: Cambridge University Press.

Wideen, M., Mayer-Smith, J., \& Moon, B. (1998). A critical analysis of the research on learning to teach: Making the case for an ecological perspective on inquiry. Review of Educational Research, 68, 130-178.

Wilhelm, J. D. (1997). You gotta BE the book: Teaching engaged and reflective reading with adolescents. New York: Teachers College Press.

Zeichner, K. M., \& Gore, J. M. (1990). Teacher socialization. In W. R. Houston (Ed.), Handbook of research on teacher education (pp. 329-348). New York: Macmillan.

PETER SMAGORINSKY is professor in English education at The University of Georgia. His research interests are centered on activity theory approaches to studying school-based literacy and teacher thinking relative to literacy instruction. His recent article, "Acquiescence, Accommodation, and Resistance in Learning to Teach within a Prescribed Curriculum," coauthored with Andrea Lakly and Tara Star Johnson, is the recipient of the National Council of Teachers of English's Janet Emig Award for the article published in the journal English Education that most contributes to the field's thinking about English teacher education and most informs the field's research.

LESLIE SUSAN COOK is a doctoral candidate in English education at The University of Georgia. Her dissertation research focuses on the mediational tools used by adolescent and young adult women diagnosed with depressive disorders to construct their identities. She has coauthored articles recently published in Elementary Education and Journal of Teacher Education. 
TARA STAR JOHNSON is a doctoral candidate in English education at The University of Georgia. Her dissertation research focuses on the body and desire in the careers of young woman teachers. She is cowinner of the Janet Emig Award presented by the National Council of Teachers of English for "Acquiescence, Accommodation, and Resistance in Learning to Teach within a Prescribed Curriculum." 
Copyright $\odot 2003$ EBSCO Publishing 